\title{
A Study of Outcome of Labour in Primigravida With High Head at Term
}

\author{
Dewan Shahida Banu', Rowshan Hosne Jahan², Faiza Chowdhury³, Zinat Begum', Shahnaz Akter Jahan', \\ Shafeya Khanam 6
}

\begin{abstract}
Objective: This prospective study was carried out to see the effect of engagement of foetal head at term in primigravidae women.

Materials and Methods: The study was conducted in the Department of Obstetrics \& Gynaecology, Sir Salimullah Medical College \& Mitford Hospital (SSMC \& MH), Dhaka from June, 2006 to December, 2006. The study included 1440 women who were admitted in the hospital during the above mentioned period. All women were examined to see the engagement of foetal head by the rule of 5 at or after 38 weeks pregnancy. Of them, $262(18.2 \%)$ presented with engagement of foetal head and $1178(81.8 \%)$ without foetal head engagement. Main outcome measure was the effect of engagement of foetal head at term in primigravidae women. Foeto-maternal outcomes were recorded by clinical observation.

Result: No significant differences were found in terms of demographic and anthropometric characteristics (like age, height and weight) between primigravidaewomen who had engaged foetal head and women who did not have foetal head engaged ( $p=0.969 ; p=0.258$ and $p=0.139)$. Three-quarters $(74.96 \%)$ of the patients at presentation were in labour and the rest were not in labour. Duration of labour was significantly higher in non-engaged group compared to those who had foetal head engaged.The incidence of non-engagement of foetal head in nulliparous women at or after 38 weeks of pregnancy was $81.8 \%$; but only $11.5 \%$ of them had cephalo-pelvic disproportion (CPD). The incidence of vaginal delivery in the non-engaged and engaged group was $36.9 \%$ and $66.1 \%$ respectively. Most of the patients underwent caesarean section due to foetal distress and indications other than CPD.
\end{abstract}

Conclusion: The findings of the study suggest that the obstetricians should take a conservative attitude and a non-engaged foetal head at term in a primigravid woman should not by itself be an indication for caesarean section.

Key words: Prmigravida high foetal head (non-engagement), cephalopelvic disproportion etc.

\section{Introduction:}

It is generally believed that high foetal station in primigravida in labour near term may indicate a threat to the normal progress of labour because of foeto-pelvic disproportion or obstruction of the foetal passage by tumor or the placenta. The concept held by obstetricians and stated in standard textbooks is that the foetal head engages in the maternal pelvis in the last four weeks of pregnancy. ${ }^{1}$ Engagement of the foetal head is a vital event in the process of labour. Once the head is engaged, it excludes cephalo-pelvic

\section{Authors' information: \\ ${ }^{1}$ Dr. Dewan Shahida Banu, Assistant Professor, Department of Obstetrics \& Gynaecology, Shaheed Tajuddin Ahmad Medical College, Gazipur \\ ${ }^{2}$ Dr. Rowshan Hosne Jahan, MBBS, DGO, FCPS (Obstetrics \& Gynaecology), Senior consultant, Maternal And Child Health Training Institute (MCHTI), Dhaka \\ ${ }^{3}$ Dr. Faiza Chowdhury, MPH (Student), Hospital Management, National Institute of Preventive and Social Medicine (NIPSOM), Dhaka. \\ ${ }^{4}$ Dr. Zinat Begum, Assistant Professor, Department of Gynae \& Obstetrics, Dhaka Medical College, Dhaka. \\ ${ }^{5}$ Dr. Shahnaz Akter Jahan, Assistant Registrar, MS (Obstetrics \& Gynaecology), Central Police Hospital, Rajarbag, Dhaka, 1000. \\ ${ }^{6}$ Dr. Shafeya Khanam, MBBS, BCS (Health), FCPS, MS, Associate Professor (Obstetrics \& Gynaecology), Faridpur Medical College \& Hospital, Faridpur.}

Correspondence: Dr. Dewan Shahida Banu, Phone: +880 1730038487 E-mail:fcshama@hotmail.com 
disproportion (CPD) at least at the level of pelvic inlet. $^{2}$ For this, obstetricians generally feel that non-engagement of foetal head at term in nulliparous women always calls for re-evaluation of the whole cephalo-pelvic relationship. Scher and $U t_{i a n}{ }^{3}$ reported that lower rate of engagement of foetal head before labour in the non-white patients and incidence of CPD is different in different racial group. Engagement of foetal head not only depends upon the size of the foetal head and maternal pelvis, but it is also influenced by pelvic inclination, race and ethnic groups..$^{4-5}$ The greater inclination of the pelvic inlet and narrow sagital diameter of pelvic inlet delay in engagement of the foetal head in Nigerian as compared to Europeans. In the Negroid primigravida however, non-engagement of the foetal head in the absence of CPD is a common feature. ${ }^{3}$ This has been attributed to the high angle of inclination of pelvic brim in that population. Diagnosis of disproportion cannot be made unless uterine action is adequate. ${ }^{2}$ The special significance of CPD is that it commits young women to caesarian section at early delivery. ${ }^{5}$ This places a responsibility on the obstetrician to ensure that initial diagnosis is correct. This aspect of problem has much significance in the general management of labour. Often in primigravida the inefficient labour is the expression of dispropotion. ${ }^{2}$

In Bangladesh it has been observed that in majority of the primigravida, head remains unengaged till labour. The incidence of engagement of foetal head at term in the nulliparous women with cephalic presentation is not known even in the absence of CPD or any other complications. Safe delivery within a reasonable time is the only proof of the functional capacity of a pelvis and failure to achieve this raises suspicion of disproportion, which is usually due to inefficient uterine contraction. This study was undertaken to find the incidence of engagement of foetal head at term in primigravida, the incidence of engagement of head at 36 weeks of pregnancy in case of early labour, the duration of labour, mode of delivery and foeto-maternal outcome.

\section{Materials \& Methods:}

This prospective clinical study was carried out in the Department of Obstetrics \& Gynaecology of Sir Salimullah Medical College \& Mitford Hospital (SSMC \& MH), Dhaka over a period of 6 months from June 2006 to December 2006. This is a tertiary level teaching hospital.The study included 1440 women who were admitted in the hospital during the above mentioned period. All women were examined to see the engagement of foetal head by the rule of 5 at or after 38 weeks pregnancy. Of them, 262(18.2\%) cases presented with engagement of foetal head and $1178(81.8 \%)$ without foetal head engagement. Main outcome measure was effect of engagement of foetal head at term in primigravidae women. Foeto-maternal outcomes were recorded by clinical observation. Using computer software SPSS (Statistical Package for Social Sciences) data were processed and analyzed. The test statistics used to analyze the data were descriptive statistics, Chi-square or Fisher's Exact Probability Test (for comparison of data presented in categorical scale) and Unpaired t-Test (for comparison of data presented on continuous scale). The level of significance was set at 0.05 and $p$-value $<0.05$ was considered significant.

\section{Results:}

Over three-fifth (62.3\%) of the patients belonged to the age group $21-25$ years followed $25 \% 20$ or $<20$ years and $12.7 \%$ more than 25 years (Table I). As demographic characteristics were compared between the women who had engaged foetal head and the women who did not have foetal head engaged, no significant differences were noted between the groups in terms of maternal age ( $p=$ $0.969)$, height $(p=0.258)$ and weight $(p=0.139)$ (Table II). Three-quarters (74.96\%) of the patients at presentation were in labour and the rest was not in labour (Table III). Duration of labour was significantly higher in non-engaged group compared to the women who have had foetal head engaged (Table IV). Table $V$ shows the mode of delivery of the women with engaged and non-engaged foetal head at or more than 38 weeks of pregnancy. The data show that the 
incidence of vaginal delivery in the non-engaged and engaged group was $36.9 \%$ and $66.1 \%$ respectively. The incidence of caesarean section was significantly higher in the non-engaged group compared to that in their engaged counterparts $(p<0.001)$. Of the 660 women with non-engaged foetal head, who underwent caesarean section, only $11.5 \%$ had CPD. Major causes of caesarean section was foetal distress in both head engaged and unengaged group. Other causes, their incidence and comparison are given in Fig. 1. APGAR score was low in 12 cases; of them $1(0.4 \%)$ in engaged \& $11(0.9 \%)$ in non-engaged group. They all returned to normal after resuscitation (Table VI).

TABLE I. Distribution of demographic characteristics $(n=1440)$

$\begin{array}{lcc}\text { Age (yrs) } & \text { Frequency } & \text { Percentage } \\ \leq 20 & 361 & 25.0 \\ 21-25 & 897 & 62.3 \\ >25 & 182 & 12.7\end{array}$

TABLE II. Comparison of demographic and obstetric characteristics between groups

Demographic \&

obstetric

characteristics $^{\#}$

Age (years)

Maternal Height (cm)

\begin{tabular}{ccc}
\multicolumn{2}{c}{ Foetal Head } & \\
\cline { 1 - 2 } $\begin{array}{c}\text { Non-engaged } \\
(n=1178)\end{array}$ & $\begin{array}{c}\text { Engaged } \\
(n=262)\end{array}$ & \\
$23.87 \pm 1.12$ & $22.81 \pm 0.34$ & 0.969 \\
$151.97 \pm 2.27$ & $152.01 \pm 0.50$ & 0.258 \\
$129.89 \pm 5.01$ & $123.21 \pm 1.23$ & 0.139
\end{tabular}

\# Data were analyzed using Unpaired t-Test and were presented as mean \pm SD.

\begin{tabular}{|c|c|c|}
\hline \multicolumn{3}{|c|}{$\begin{array}{l}\text { TABLE III. Distribution of patients by their presentation } \\
(n=1440)\end{array}$} \\
\hline Presentation of patients & Frequency & Percentage \\
\hline In labour & 883 & 74.96 \\
\hline Not in labour & 295 & 25.04 \\
\hline
\end{tabular}

\begin{tabular}{|c|c|c|c|}
\hline \multirow[b]{2}{*}{ Duration of labour } & \multicolumn{2}{|c|}{ Foetal Head } & \multirow[b]{2}{*}{ p-value } \\
\hline & $\begin{array}{c}\text { Non-engaged } \\
(n=1178)\end{array}$ & $\begin{array}{l}\text { Engaged } \\
(n=262)\end{array}$ & \\
\hline$<12$ hours & $640(54.3)$ & 185(70.6) & \\
\hline $12-24$ hours & $538(45.7)$ & $77(29.4)$ & \\
\hline Mean $\pm S D^{\#}$ & $12.01 \pm 4.8$ & $9.8 \pm 3.4$ & $<0.001$ \\
\hline
\end{tabular}

Figures in the parentheses denote corresponding percentage. \# Data were analyzed using Unpaired t-Test and were presented as mean \pm SD.
TABLE V. Comparison of mode of delivery between groups

\begin{tabular}{lccc} 
& \multicolumn{2}{c}{ Group } & \\
\cline { 2 - 3 } Mode of Delivery* & $\begin{array}{l}\text { Non-engaged } \\
(\mathrm{n}=1178)\end{array}$ & $\begin{array}{l}\text { Engaged } \\
(\mathrm{n}=262)\end{array}$ & p-value \\
$\begin{array}{l}\text { NVD (Normal Vaginal } \\
\text { Delivery) }\end{array}$ & $435(36.9)$ & $173(66.1)$ & \\
$\begin{array}{l}\text { VD (Vaginal Delivery) } \\
\text { with ventouse }\end{array}$ & $83(7.0)$ & $31(11.8)$ & $<0.001$ \\
$\begin{array}{l}\text { LSCS (Lower Segment } \\
\text { caesarean Section) }\end{array}$ & $660(56.1)$ & $58(22.1)$ &
\end{tabular}

Figures in the parentheses denote corresponding percentage.

* Data were analyzed using Chi-squared $\left(\chi^{2}\right)$ Test

\begin{tabular}{|c|c|c|c|}
\hline \multicolumn{4}{|c|}{$\begin{array}{l}\text { TABLE VI. Comparison of maternal perinatal outcome between } \\
\text { groups }\end{array}$} \\
\hline \multirow[b]{2}{*}{ Outcome* } & \multicolumn{2}{|c|}{ Group } & \multirow[b]{2}{*}{ p-value } \\
\hline & $\begin{array}{l}\text { Non-engaged } \\
(\mathrm{n}=1178)\end{array}$ & $\begin{array}{l}\text { Engaged } \\
(\mathrm{n}=262)\end{array}$ & \\
\hline \multicolumn{4}{|l|}{ Maternal } \\
\hline PPH & $17(1.4)$ & $7(2.7)$ & 0.160 \\
\hline Birth canal injury & $12(1.0)$ & $4(1.5)$ & 0.478 \\
\hline Wound infection & $81(6.9)$ & $8(3.1)$ & 0.020 \\
\hline Puerperal Sepsis & $11(0.9)$ & $3(1.1)$ & 0.753 \\
\hline \multicolumn{4}{|l|}{ Perinatal outcome } \\
\hline APGAR $<7$ & $11(0.9)$ & $1(0.4)$ & 0.374 \\
\hline
\end{tabular}

Figures in the parentheses denote corresponding percentage.

* Data were analyzed using Chi-squared $\left(\chi^{2}\right)$ Test

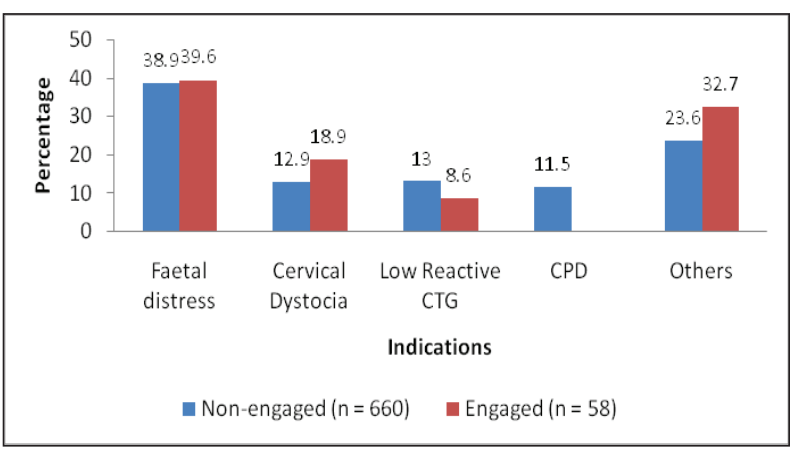

Fig. 1: Indications for caesarean section

\section{Discussion:}

The concept held by obstetrician and stated in standard text booksis that foetal head engages in the maternal pelvis in the last four weeks of pregnancy. If it does not happen, one should suspect certain problems. The incidence of nonengagement of foetal head at or $>38$ weeks of pregnancy in nuillparous women with singleton foetus with cephalic presentation in our series was $81.8 \%$. This is definitely a very high rate. Jafarey ${ }^{1}$ 
observed an incidence of $79.7 \%$ in Pakistani nulliparous women. In 1999 Ashraf et al $^{6}$ has shown $83 \%$ of non-engagement in Bangladeshi women. Our findings are consistent with that of Jafarey $^{1}$ and Fatema et al. Obstetricians generally feel that unengaged head in a primigravida at the onset of labour always calls for careful re-evaluation of the whole cephalo-pelvic inter relationship. Stipp ${ }^{7}$ considered CPD in about 55\% of all primigravida because of this one factor alone, whereas Auer and Simmon's ${ }^{8}$ considered this factor in only $10 \%$ cases. Scher and Utian ${ }^{3}$ found that there was statistically significant difference in CPD, engagement and nonengagement of foetal head in different racial groups. Engagement was only $11 \%$ in the Cape coloured and $3 \%$ of Bantu teen agers. Stream ${ }^{9}$ also found this to be true in $50 \%$ of the teenage pregnancy and Utian ${ }^{10}$ confirmed this in white patients. However, Brigg in a study of Nigerian primigravida did not find any association of non-engagement of head with angle of inclination. He found a significant difference between the mean head circumferences of the foetus that had not engaged and those that had engaged. In this study there was no significant difference between engaged and non-engaged groups of women in terms of maternal age, height and weight indicating that these variables could not influence foetal head engagement in primigravidae. Majority of the vaginal delivery in both non-engaged and engaged groups took place spontaneously and a small percentage delivered with the help of vacuum extraction. Eighty one percent of the Jafarey's ${ }^{1}$ cases delivered vaginally without increased foetal morbidity which compares well with the findings of our study.

The rate of vaginal deliveries observed in Swedish Hospital Medical Centre, Washington, was 94.6\% and rate reported by Auer and Simmons ${ }^{8}$ was $74 \%$. Ashraf and colleagues ${ }^{6}$ observed that $44.7 \%$ of women with non-engaged foetal head delivered vaginally. Most of the indications of caesarean section was due to foetal distress. This indicates that non-engagement did not always mean CPD. One should be very careful while diagnosing CPD. This is because of the fact that it commits a young woman to caesarean section at every subsequent delivery. In the study $56 \%$ of women with non-engaged foetal head needed caesarean section. But only $11.5 \%$ of them had caesarean section for CPD. O'Driscolf ${ }^{2}$ reported an incidence of CPD of $0.9 \%$ only in a series of 1000 consecutive primigravida (both with engaged and non-engaged heads). Ashraf and colleagues ${ }^{6}$ reported that only $5.82 \%$ of the women with non-engaged foetal head needed caesarean section. This indicates that the incidence of CPD is not very high even in those primigravidae women with non-engaged foetal head at term.

So in our series most of the patients underwent caesarean section due to foetal distress and other indications. So engagement of foetal head excludes CPD at least at the level of pelvic brim but opposite is not always true; that is non-engagement of the foetal head at term does not always mean CPD. Incidence of engagement of foetal head at term varies from population to population. The diagnosis of disproportion, except the gross ones, cannot be confidently made unless the patient is in labour and uterine action is adequate. ${ }^{2}$ Postpartum X-ray pelvimetry was not done in those cases who had undergone caesarean section. This is because of the fact that value of X-ray pelvimetry has been seriously questioned. ${ }^{11}$ Pelvimetry is materially focused but does not assess foetal size and presentation. ${ }^{11}$ Thomas $^{12}$ suggested that postnatal X-ray pelvimetry helps in the identification of women at particular risk of scar rupture in a subsequent labour but this was not supported by the study of Krishnamurthy et al. ${ }^{13}$ So pelvimetry should not influence management of women with non-engaged foetal head at term, except in rare instances of gross pelvic contraction. ${ }^{2}$ Moreover, an incorrect diagnosis of CPD is often made in cases of inefficient uterine action and some features of pelvic architecture is accepted as evidence in support of this error. ${ }^{14}$ Although the duration of labour was significantly higher in non-engaged group as opposed to the engaged group, there was no major maternal complications and no maternal deaths in these cases. The APGAR Score of all the babies was good, except 11 
in non-engaged group and 1 in engaged group who returned to normal after resuscitation. There was no perinatal death in this study.

\section{Conclusion:}

It may be concluded that engagement of foetal head before labour is neither a constant feature in a primigravida women, nor necessarily a criterion for successful vaginal delivery. This study reported that the incidence of non-engaged foetal head at or more than 38 weeks of pregnancy in the nulliprous pregnant women is quite high. A good number of them had vaginal delivery. The incidence of CPD is quite low in them. The findings of the study suggest that the obstetricians should take a conservative attitude and a non-engaged head at term in primigravida women should not by itself be an indication for caesarean section.

\section{References:}

1. Jafarey SN. Unengaged Foetal Head in Pakistani Primigravida: Frequency and outcome. Asia-Oceania J Obstet Gynaecol 1988;14(1):13-16.

2. O'Driscoll K, Jackson RJA \& Gallagher JT. Active management of Labour and cephalopelvic disproportion. J Obstet Gynaecol Brit Common 1970;77 (5):385-89.

3. Scher J \& Utian WH. Teenage pregnancy: An interracial study. J Obstet Gynaecol Brit Comn 1970;77:259-62.

4. Briggs NO. Engagement of foetal head in the Negro-primigravida. Br J Obstet Gynaecol 1981:88: 1086-89.
5. Kolawole TM, Adamu SP \& Evans KT. Comparative pelvimetric measurements in Nigerian and Welsh women. Clin Radial 1978;29:85-90.

6. Ashraf $F$, Hossain MA, Parveen T. Engagement of the foetal at term in Nulliparous Bangladeshi Women; prevalence andoutcome. Bangladesh J Obs Gyne 1999; 14(1):3-5.

7. Stipp CG. The primigravida in labor with high fetal station:A study of 1,209 hospital records of obstetric patients. Am J Obstet Gynaecol 1969;104(2):267-70. DOI:http://dx.doi.org/10.1016/0002-9378(69)90674-7.

8. Auer ES \& Simmons.The Floating Fetal Head in the Primipara at Term. Amer J Obstet Gynecol 1949;58:291.

9. Stearn RH. The Adolescent Primigravida. Lancet 1963;2(7317):1083-5.

10. Utian WH. Obstetrical implications of pregnancy in primagravidae aged 16 years or less. British Medical Journal 1967;2(5554):734-6.

11. Walter J \& Hannah MD. X-ray pelvimetry - a critical appraisal. Am J Obstet \& Gynaecol 1965;91:333.

12. Thoms $\mathrm{H}$. The clinical application of roentgen pelvimetry and a study of the results in 1,100 white women. AJOG 1941; 42(6): 957-75.DOI:http://dx.doi.org/10.1016/ S0002-9378(41)90262-4

13. Krishnamurthy S, Fairlie F, Cameron AD, Walker JJ \& Mackkenzie JR. The role of postnatal X-ray pelvimetry after caesarian section in the management of subsequent delivery. Br J Obstet Gynaecol 1991;98: 716-81.

14. Strachan GI. Discussion: The Present Conception of Trial Labour. Proc R Soc Med 1952;45(8):527-35. 